\title{
Micro VS Macro Goal Framework in College
}

\author{
Cheon-woo Han \\ School of Education, The University of Texas, Tyler, United States \\ *Corresponding author: chan@uttyler.edu
}

\begin{abstract}
This quasi-experimental study focused on the research hypothesis that students' individual achievement goals toward each instructional component predict their perceptions of classroom goals. A total of 173 college students from an introductory educational psychology course participated in this study. Elliot and Church's [23] achievement goals questionnaire and Urdan's [21] perception of classroom goals were administered at pre- and post-measures during one academic semester. Multiple regression analysis was employed to determine whether or not students' individual achievement goals toward each instructional task predicted their perceptions of classroom goals. The results showed that participants' achievement goals toward in-class activities were significantly associated with their perceptions of classroom goals.
\end{abstract}

Keywords: achievement goals, class goals, alternative framework

Cite This Article: Cheon-woo Han, "Micro VS Macro Goal Framework in College." American Journal of Educational Research, vol. 5, no. 12 (2017): 1191-1194. doi: 10.12691/education-5-12-3.

\section{Objectives}

In order to understand students' achievement goals in class, diverse investigations have been conducted. One line of this research has been directed at understanding the relations between class goal structures and individual goal orientations. Theorists have examined the relations between students' perceptions of class goals, learning outcomes, and their individual achievement goals [1-6,19]. Research on this area has generally found a positive correlation or association between students' perceptions of class goal structures and their respective personal goals, whereby the class goal structures influence personal goals (e.g., performance goal structure $\rightarrow$ individual performance goals, mastery goal structure $\rightarrow$ individual mastery goals).

However, is there the opposite direction between two constructs? I wanted to investigate whether students' individual achievement goals could predict their perceptions of class goal structures. I hypothesized that students' perceptions of classroom goals would be affected by their individual goal pursuit of instructional tasks. If I could find any interesting relations between them, I would be able to suggest a totally different perspective of research to investigate achievement goal theory.

\section{Theoretical Framework}

\subsection{Class goal Structures}

Substantial research and theorizing have addressed not only how classroom environments affect students' learning and relevant outcomes, but also how learning environments influence students' views and purposes of learning. Ames and Archer [1] showed that students' perceptions of classroom climate were related to the adoption of individual goal orientation and use of learning strategies. After that finding, considerable research has focused on describing how classroom goal structures elicit different motivational patterns and how these goals are reflected in the classroom context $[3,7,8,9,10,11]$. Research on achievement motivation has shown that situational demands can affect the salience and adoption of specific goals, which leads to differential patterns of cognition, affect, and behavior [1,12,13]. For example, Phan [20] examined the effects of classroom learning environment on students' achievement goals and reflective thinking practices for a sample of 298 secondary school students. Results showed that the different facets of the classroom environment in terms of involvement, students' cohesiveness, task orientation, and satisfaction exerted direct and indirect influences on students' achievement goals, reflective thinking practices, and academic performance.

\subsection{Achievement Goals}

Achievement goal is a motivational construct that affects how an individual approaches and interprets tasks [14]. The concept is associated with beliefs in the controllability of personal attributes such as intellectual ability [15], how individuals view effort expenditure [7,8], and how individuals respond to task difficulties or task failure [15]. Achievement goals generally have been considered to be cognitive representations, rather than implicit needs or drives, with an end state that is centered on competence -either developing (mastery) it or demonstrating (performance) it. Recent research has focused on identifying different types of goals among students, the motivational processes that are associated 
with theses different goals, and the conditions that elicit them. In the present study, achievement goal is defined as the behavioral intentional system that decides learning style and is described based on Ames and Archer's achievement goal orientation term.

\subsection{Relations between Classroom Structures and Achievement Goals}

As discussed above, researchers have been considering the relationship between students' perceptions of the goal structures in their classrooms, their personal goal orientations, and their approaches to learning $[1,3,4]$. For example, Ryan et al (1998) investigated how classroom goal structure was related to avoidance help seeking for 516 students across seventh grade math classrooms. Results indicated that students' perceptions of a mastery classroom goal structure were associated with a lower level of help avoidance, whereas their perceptions of a performance classroom goal structure were associated with a higher level of avoiding help. With the same manner, Urdan [21] reported that performance goal structures were positively associated with self-handicapping. Achievement goal theory is useful for not only providing a framework for studying individual differences in motivation but also analyzing the influence of classroom environments' on students' motivation and learning.

Some studies have suggested that perceptions of the classroom goal structures may exert a direct effect and/or interaction effect with personal goals on outcome measures as well [16,17,18]. Murayama and Elliot [18] explored the joint influence of personal achievement goals and classroom goal structures on achievement-relevant outcomes. They identified three models -direct, indirect, and interaction effect model- with a sample of 1,578 high school students. A direct effect model posits that classroom goal structures directly influence achievementrelevant outcomes such as intrinsic motivation and academic self-concept. Several studies in the class goal literature have utilized this model. Some of them have examined the effects of classroom goal structures alone $[1,13,22,24,25]$ or measured individual goals but conducted separate sets of analyses [26]. Second, an indirect effect model posits that classroom goal structures indirectly influence achievement-relevant outcomes through their impact on the adoption of personal achievement goals. That is, goal structures are thought to prompt the adoption of personal goals, and personal goals are considered as having a proximal influence on outcomes. Most of studies in the literature have used this model to examine relations from goal structures to individual goals and outcomes [27-30]. The last model is an interaction effect model, which suggests that classroom goal structures moderate the influence of individual achievement goals on outcomes. Only a few studies have explored directly the relations between goal structures and personal goal adoptions, moderations, and mixed effects on achievement-relevant outcomes $[6,16,17]$. Linnenbrink [17] conducted a quasi-experimental study in which she measured 237 upper elementary students' goals and manipulated classroom goal structures by controlling teachers with specific guidelines and suggestions for class. She did not find any significant interaction effect between classroom goals and individual goals on achievementrelevant outcomes. The study being proposed in this dissertation adopts the indirect model examining logical paths between classroom goal structures and the pursuit of individual achievement goals.

\section{Method}

\subsection{Participants}

A total of 186 college students (76 males, 110 females) from a lower division educational psychology course at a large Southwestern university participated in this study. Ages ranged from 18 to $25(M=18.66, S D=1.19)$ and their majors were also diverse.

\subsection{Measures}

Achievement goals. The student's individual achievement goals were measured using Elliot and Church's [23] questionnaire to assess participants' adoption of mastery, performance-approach, and performance-avoidance achievement goals toward each instructional task in their class at pre- and post-test. This scale consists of 18 items, six for each achievement goal. Example items are: 'I want to learn as much as possible from this class' (mastery goal); 'My goal in this class is to get a better grade than most of the students' (performance-approach goal) and 'I just want to avoid doing poorly in this class' (performance-avoidance goal). All questions about achievement goals for each instructional task were provided with a proper leading passage based on each task.

Perception of classroom goals. To investigate how students perceived their classroom goal structures, I used 12 items assessing students' perceptions of classroom mastery and performance goals. Urdan [21] developed the questionnaire based on existing class goal measures and it showed acceptable internal reliability ( $\alpha=.87$ and .89). Sample items from the classroom mastery and performance goal structure scales included respectively "In this class, it is important to understand concepts, not just memorize them." and "In this class, getting a good grade is the main goal."

\subsection{Procedures}

During the first week of the class, students received a detailed syllabus with course instruction and expectations from their instructor. In this course, students were assigned four major different tasks; three exams, four writing assignments, ten in-class quizzes, eight in-class activities. On the last day of introduction week, participants were asked to respond to their first measure, which was the pre-assessment of their beginning perceptions of the classroom goals. Collection of achievement goals was spread throughout the semester as follows (Figure 1). Finally, the post-assessment of classroom goal perception was administered. 


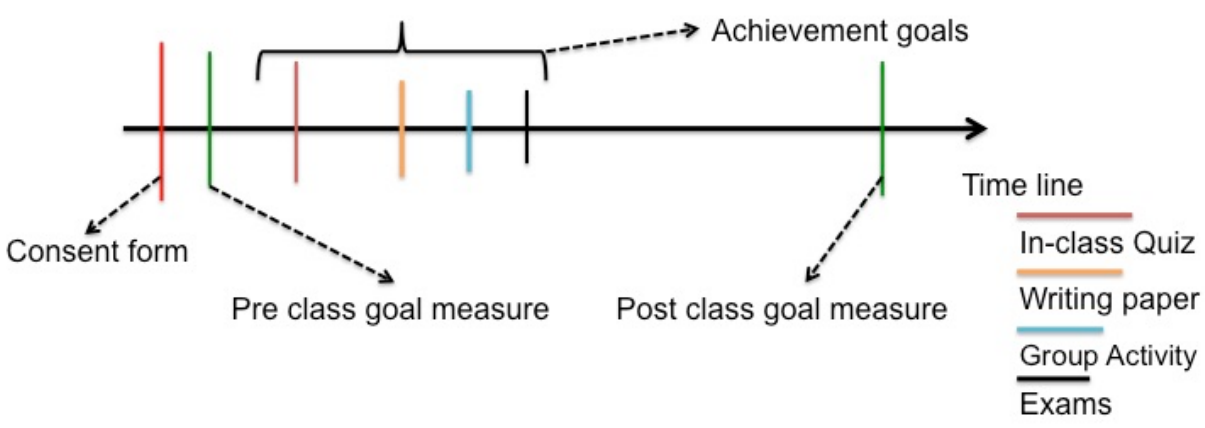

Figure 1. Research time line

\section{Results}

\subsection{Preliminary Analysis}

Before submitting these data to statistical analysis procedures, I inspected the univariate distributions of all variables, to ensure that they were approximately normal. The reliability of the instruments was calculated by a common psychometric measure of test and scale reliability, Cronbach's alpha, which was calculated for each measure in the study to assess internal consistency of the instruments. The measures' reliability coefficients range from .71 to .90 , which are strong.

\subsection{Primary Analysis}

Multiple regression analysis was used to examine whether individual achievement goals toward instructional tasks predicted students' perceptions of classroom goals. I conducted a series of regression analyses for predicting pre- and post-measures of class goal perceptions using the enter method. There was no significant achievement goal predictor for pre-measures of students' class goals perception. Then, I entered only individual mastery goals for each instructional task to predict the perception of mastery-oriented class goals. There was no significant individual mastery goals predictor for the classroom goals perception. Likewise, students' performance-approach and performance-avoidance goals toward each task did not predict their perceptions of performance class goals.

However, the achievement goals for in-class activities are significantly associated with students' perception of class goals at the post-measures. The perception of mastery classroom goals was predicted by students' mastery goals ( $\beta=.67, t=5.71, p<.001)$ and performance-avoidance goals $(\beta=-.19, t=-2.00, p<.05)$ toward in-class activities. Also, students' performance-approach $(\beta=.39, t=2.81, p<.01)$ and performance-avoidance goals $(\beta=.31, t=2.99, p<.01)$ for in-class activities significantly predicted their perception of performance-oriented class goals. Thus, as students had high mastery goals toward their in-class activities, they perceived their class as more mastery-oriented. Likewise, students with high performance goals for activities reported high levels of performance-oriented perception in class. The summary of results is presented at Table 1. In order to check multicollinearity among the predictor variables, I calculated the tolerance statistic and all values were greater than .20, thus can be inferred as no multicollinearity issue.

Table 1. Summary of regression analyses between post-class goals and activities

\begin{tabular}{|c|c|c|c|c|c|c|c|}
\hline & $\mathrm{B}$ & $\beta$ & $\mathrm{t}$ & $p$ & Adj. $\mathrm{R}^{2}$ & $\mathrm{~F}$ & $p$ \\
\hline \multicolumn{5}{|c|}{ Predicted variable: Perception of mastery class goals } & .43 & 11.94 & .00 \\
\hline Activitiy_MAS & .49 & .67 & 5.71 & .00 & & & \\
\hline Activitiy_PAP & .03 & .05 & .41 & .68 & & & \\
\hline Activitiy_PAV & -.15 & -.19 & -2.00 & .04 & & & \\
\hline \multicolumn{5}{|c|}{ Predicted variable: Perception of performance class goals } & .37 & 9.53 & .00 \\
\hline Activitiy_MAS & -.03 & -.03 & -.24 & .81 & & & \\
\hline Activitiy_PAV & .29 & .31 & 2.99 & .00 & & & \\
\hline
\end{tabular}

Note. MAS = mastery; $\mathrm{PER}=$ performance; $\mathrm{PAP}=$ performance-approach; $\mathrm{PAV}=$ performance-avoidance; $\mathrm{B}=$ unstandardized coefficient; $\beta=$ standardized coefficient; Adj. $\mathrm{R}^{2}=$ adjusted r-square value.

\section{Discussion}

I hypothesized that students' perceptions of classroom goals would be affected by their individual goal pursuit of instructional tasks. Since there is no current research on this relation, this also needs to be considered as an exploratory hypothesis. In order to explore possible relations, I conducted a series of multiple regression analyses for predicting pre- and post-measures of class goal perceptions with individual goal orientations. There was not any significant personal achievement goals predictor for pre-measures of participants' classroom structures. This might be because of research design issues; specifically the pre-measures of perceived classroom goals were collected at the very beginning of the semester. Even though instructors tried to explain clearly about requirements, expectations, and guidelines for the instructional tasks, students could not become aware of classroom climate at that point.

At the posttest, however, participants' achievement goals toward in-class activities were significantly associated with their perceptions of classroom goals. In 
other words, if students had high levels of mastery goals for participating in a class activity, they were more likely to perceive their classroom climate as mastery-oriented. Also, their performance-avoidance goals for an activity were negatively associated with the perceptions of mastery-oriented class goals. In terms of predicting performance-oriented classroom structures, individual performance goal orientations (both performance-approach and performance-avoidance) for in-class activities were also significantly assessed. Students pursuing high levels of the two performance goals for in-class activities were more likely to perceive their classroom structure as performance-oriented. Therefore, the results suggest that instructors should elaborate and embed mastery-aimed activities in class for students to adopt high perceptions of mastery-oriented classroom structures.

As I mentioned above, I want to explore how students' individual achievement goals affect their perceptions of classroom structures. I expected the small individual goals to predict big classroom goal structures. Particularly, I hypothesized that student's pursuing of achievement goals toward each instructional component could build up their perceptions of classroom structures. For this reason, I would name 'Micro VS Macro goal framework' for the relations between two constructs. Even though I could not verify significant relations in all instructional tasks, this area would be very interesting for future studies.

\section{References}

[1] Ames, C., \& Archer, J. (1988). Achievement goals in the classroom: Students' learning strategies and motivation processes. Journal of Educational Psychology, 80(3), 260-267.

[2] Anderman, E. M., \& Midgley, C. (1997). Changes in achievement goal orientations, perceived academic competence, and grades across the transition to middle-level schools. Contemporary Educational Psychology, 22(3), 269-298.

[3] Church, M. A., Elliot, A. J., \& Gable, S. L. (2001). Perceptions of classroom environment, achievement goals, and achievement outcomes. Journal of Educational Psychology, 93(1), 43-54.

[4] Meece, J. L., \& Miller, S. D. (2001). A longitudinal analysis of elementary school students' achievement goals in literacy activities. Contemporary Educational Psychology, 26(4), 454-480.

[5] Roeser, R., Arbreton, A., \& Anderman, E. (1993). Teacher characteristics and their effects on student motivation across the school year. In annual meeting of the American Educational research Association, Atlanta, GA.

[6] Wolters, C. A. (2004). Advancing Achievement Goal Theory: Using Goal Structures and Goal Orientations to Predict Students' Motivation, Cognition, and Achievement. Journal of Educational Psychology, 96(2), 236-250.

[7] Ames, C. (1992a). Achievement goals and the classroom motivational climate. In D. H. Schunk \& J. L. Meece (Eds.), Student perceptions in the classroom. (pp. 327-348). Hillsdale, NJ England: Lawrence Erlbaum Associates, Inc.

[8] Ames, C. (1992b). Classrooms: Goals, structures, and student motivation. Journal of Educational Psychology, 84(3), 261-271.

[9] Ciani, K. D., Middleton, M. J., Summers, J. J., \& Sheldon, K. M. (2010). Buffering against Performance Classroom Goal Structures: The Importance of Autonomy Support and Classroom Community. Contemporary Educational Psychology, 35(1), 88-99.

[10] Meece, J. L., Anderman, E. M., \& Anderman, L. H. (2006). Classroom goal structure, student motivation, and academic achievement. Annual Review of Psychology, 57, 487-503.

[11] Urdan, T., \& Schoenfelder, E. (2006). Classroom Effects on Student Motivation: Goal Structures, Social Relationships, and Competence Beliefs. Journal of School Psychology, 44(5), 331-349.
[12] Covington, M. V., \& Omelich, C. L. (1984). Task-oriented versus competitive learning structures: Motivational and performance consequences. Journal of Educational Psychology, 76(6), 1038-1050.

[13] Ryan, A. M., Gheen, M. H., \& Midgley, C. (1998). Why do some students avoid asking for help? An examination of the interplay among students' academic efficacy, teachers' social-emotional role, and the classroom goal structure. Journal of Educational Psychology, 90(3), 528-535.

[14] Dweck, C. S. (1986). Motivational processes affecting learning. American Psychologist, 41(10), 1040-1048.

[15] Dweck, C. S., \& Leggett, E. L. (1988). A social-cognitive approach to motivation and personality. Psychological Review, 95(2), 256-273.

[16] Lau, S., \& Nie, Y. (2008). Interplay between personal goals and classroom goal structures in predicting student outcomes: A multilevel analysis of person-context interactions. Journal of Educational Psychology, 100(1), 15-29.

[17] Linnenbrink, E. A. (2005). The Dilemma of PerformanceApproach Goals: The Use of Multiple Goal Contexts to Promote Students' Motivation and Learning. Journal of Educational Psychology, 97(2), 197-213.

[18] Murayama, K., \& Elliot, A. J. (2009). The joint influence of personal achievement goals and classroom goal structures on achievement-relevant outcomes. Journal of Educational Psychology, 101(2), 432-447.

[19] Han, C. (2016). Change and Stability in Achievement Goals based on Instructional Tasks of a College Classroom. American Journal of Educational Research, 4(14), 999-1007.

[20] Phan, H. P. (2008). Achievement goals, the classroom environment, and reflective thinking: A conceptual framework. Electronic Journal of Research in Educational Psychology, 6(3), 571-602.

[21] Urdan, T. (2004). Predictors of academic self-handicapping and achievement: Examining achievement goals, classroom goal structures, and culture. Journal of Educational Psychology, 96(2), 251-264.

[22] Midgley, C., Kaplan, A., Middleton, M., Maehr, M. L., Urdan, T., Anderman, L. H., \& Roeser, R. (1998). The development and validation of scales assessing students' achievement goal orientations. Contemporary Educational Psychology, 23(2), 113-131.

[23] Elliot, A. J., \& Church, M. A. (1997). A hierarchical model of approach and avoidance achievement motivation. Journal of Personality and Social Psychology, 72(1), 218-232.

[24] Patrick, H., Anderman, L. H., Ryan, A. M., Edelin, K. C., \& Midgley, C. (2001). Teachers' communication of goal orientations in four fifth-grade classrooms. Elementary School Journal, 102(1), 35-58.

[25] Turner, J. C., Midgley, C., Meyer, D. K., Gheen, M., Anderman, E. M., Kang, Y., \& Patrick, H. (2002). The classroom environment and students' reports of avoidance strategies in mathematics: A multimethod study. Journal of Educational Psychology, 94(1), 88106.

[26] Gutman, L. M. (2006). How student and parent goal orientations and classroom goal structures influence the math achievement of African Americans during the high school transition. Contemporary Educational Psychology, 31(1), 44-63.

[27] Bong, M. (2005). Within-grade changes in Korean girls' motivation and perceptions of the learning environment across domains and achievement levels. Journal of Educational Psychology, 97(4), 656-672.

[28] Church, M. A., Elliot, A. J., \& Gable, S. L. (2001). Perceptions of classroom environment, achievement goals, and achievement outcomes. Journal of Educational Psychology, 93(1), 43-54.

[29] Greene, B. A., Miller, R. B., Crowson, H. M., Duke, B. L., \& Akey, K. L. (2004). Predicting high school students' cognitive engagement and achievement: contributions of classroom perceptions and motivation. Contemporary Educational Psychology, 29(4), 462-482.

[30] Roeser, R. W., Midgley, C., \& Urdan, T. C. (1996). Perceptions of the school psychological environment and early adolescents' psychological and behavioral functioning in school: The mediating role of goals and belonging. Journal of Educational Psychology, 88(3), 408-422. 